\title{
Altruism in wolves explains the coevolution of dogs and wolves: A response to Jouventin, Christen, and Dobson
}

\author{
Sylvain Fiset \\ Sylvain Fiset (ylvain.fiset@umoncton.ca), Université de Moncton in Edmundston, Edmundston, NB, Canada
}

\begin{abstract}
Jouventin et al. suggest that altruistic behaviour in wolves, demonstrated by modern wolves towards their human caretakers, was exploited by prehistoric men and explains the possible coevolution of dogs and humans. In this response paper, I question their observations and propose alternative explanations for them. I also suggest various hypotheses that the authors need to explore in regards to the evolution of altruism behaviour in wolves towards humans. Finally, I also question how prehistoric humans could have raised wolf pups and why archeological evidence does not support this hypothesis.
\end{abstract}

Keywords: wolf, dog, altruism, domestication, evolution

In their article, Jouventin et al. (2016) suggest that altruism behaviour, demonstrated by modern wolves towards their human caretakers, explains the possible coevolution of dogs and humans. More specifically, these authors propose that altruistic behaviour in wolves (e.g. ability to take care of their conspecifics and provide protection) was exploited by prehistoric men, some 35,000 years ago. By means of a systematic selection process, these prehistoric men would have raised less aggressive and fearful wolf pups. Once adults, these wolves would have provided protection to humans and assisted them in hunting large prey. Interestingly, this hypothesis is in line with similar ideas in the field of cbanine cognition, suggesting that dogs' and humans' cognitive and physiological processes coevolved during the last 15,000-32,000 years (e.g. see Hare et al. 2004, Nagasawa et al. 2015). Although I usually encourage new ideas, I have some concerns regarding the hypothesis advanced by Jouventin et al. (2016).

The examples provided by the authors to support their hypothesis about the possible role of altruism in wolves towards their "human park members" are limited, and almost anecdotic. Very few details (e.g. duration of events, age of the wolf at the time of the event, etc.) are provided to evaluate the validity of the observations described by Jouventin et al. (2016). For instance, how often did Jouventin's family members attempt to jump out the window? In the same vein, how many times did they mimic disputes, etc.? But here, however, I have to admit that I did not have the chance to read Pierre Jouventin's (2012) book «Kamala, une louve dans ma famille». Perhaps more details are available in it. I also wonder if the altruism behaviour observed by Jouventin could be explained by any form of instrumental or pavlovian conditioning. Jouventin's wolf ("Kamala"), was kept indoors most of the time in a relatively small flat, with her human park members. Thus, could it be possible that Kamala' unique exposure to humans has favoured, over the years, a gradual learning of her altruistic behaviour via positive reinforcement by her 'human conspecifics'?

Moreover, I think the authors need to address a few fundamental questions in regards to the evolution of wolves' altruistic behaviour. For instance, did the common ancestor of dogs and wolves also demonstrate the same level of altruism? Could it be possible that altruism in wolves evolved after they split from dogs? Just as physiological processes (e.g. see Trut 1999, 2001), under particular circumstances, psychological and behavioural processes can be altered during a 
relatively short period of time (for a review, see Dukas 2004). Thus, it is possible that what was observed by Jouventin with Kamala did not exist in wolf/dog's ancestors and is simply the result of a recent evolution in modern wolves.

In addition, although the field of evolutionary genetics suggests that wolves and dogs diverged from a common ancestor about 35,000 years ago (Skoglund et al. 2015), Miklosi (2015) judiciously pointed out that archaeological evidence does not support the domestication of dogs before 15,000 BC. More specifically, he wrote (p. 131): "One may also note that if dogs had been domesticated during these times, they should have been represented in cave art that depicts significant events in the life of prehistoric humans. Artists depicted wild animals, hunting humans, and other symbols, so it is quite likely that they would have portrayed the dog as well, if they had owned one." Based on this last argument, which is in contradiction with the authors' main hypothesis suggesting that proto-domesticated wolves contributed to hunting behaviour in prehistoric men, I wonder what the authors' counterarguments are here.

In line with this argument, Jouventin et al. (2016) do not provide sufficient details about how palaeolithic men were able to capture wolf pups, raise them, and select the less aggressive and fearful wolves, especially considering that these men were nomadic people. Indeed, even for modern men, taking care of wolf pups to make them tolerable to humans is a 24-hour job that lasts several months (see Klinghammer and Goodmann 1987). Given the conditions under which prehistoric men were living, I wonder if they could afford the time and energy required to nurse these pups. In addition, although the hypothesis proposed by Jouventin et al. (2016) is appealing, the authors also need to explain how prehistoric men were able to «control » the wolves to help them to hunt or fight against other tribes. In addition, making reference to the latter, Miklosi (2015: 127) also pointed out: "At the moment it is less clear how mobile hunting humans could prevent these wolflike populations living in their neighbourhood from mixing [with wild wolves]."

Finally, Miklosi (2015), by combining recent theories about dog domestication, presents a relatively straightforward evolutionary description of the process of dog domestication. In short, Miklosi suggests, based on molecular and archeological evidence, that the selection of free-ranging wolves possibly occurred around 10,000-5,000 years BC, that is, several thousand years after the first wolves began to follow prehistoric men to take advantage of the food deposits they left behind. Since Jouventin et al. (2016) propose a much earlier period of time for the selection process of wolves by prehistoric men-well before post-palaeolithic men developed agriculture (around 9,000 BC)-I wonder how they could conciliate their view with the one proposed by Miklosi.

Overall, although my comment may sound negative, I have to admit that Jouventin et al. (2016) are proposing an interesting and exciting new hypothesis, which needs to be discussed and evaluated by the scientific community. The hypothesis that altruism in wolves may have contributed to the possible coevolution of dogs and humans is, at least, plausible, and only time will tell us if the authors were correct. Nevertheless, as a first step for developing, elaborating and reinforcing their hypothesis, I strongly believe that Jouventin et al. (2016) need to address the points I have highlighted in my present commentary.

\section{Acknowledgements}

This work was supported by a discovery grant from the Natural Sciences and Engineering Research Council of Canada (NSERC) (No. RGPIN-2014-04688). I thank Catherine Fiset for revising a previous version of this manuscript. Current address: Sylvain Fiset, Secteur des Sciences Humaines, Edmundston, New-Brunswick, Canada, E3V 2S8, email: sylvain.fiset@umoncton.ca.

\section{References}

Callaway, E. 2013. Dog genetics spur scientific spat. Nature 498: 282-283. CrossRef

Dukas, R. 2004. Evolutionary biology of animal cognition. Annual Review of Ecololgy, Evolution, and Syltematics 35: 347-374. CrossRef

Hare, B., Brown, M., Williamson, C. and Tomasello, M. 2002. The domestication of social cognition in dogs. Science 298: 1634-1636. CrossRef

Jouventin, P., Christen, Y., and F.S. Dobson. 2016. Altruism in wolves explains the coevolution of dogs and humans. Ideas in Ecology and Evolution 9: 411. CrossRef

Klinghammer, E. and Goodmann PA 1987. Socialization and management of wolves in captivity. Pages 31-61 in Frank, D.H., editor. Man and wolf: advances, issues and problems in captive wolf research. Junk Publishers, Dordrecht, The Netherlands.

Miklosi, A. 2015. Dog behaviour, evolution and cognition, 2nd edition. Oxford University Press, Oxford, UK.

Nagasawa, M., Mitsui, S., En, S., Ohtani, N., Ohta, M., Sakuma, Y. et al 2015. Oxytocin-gaze positive loop and the coevolution of human-dog bonds. Science 348: 333-336. CrossRef

Skoglund, P.E., Ersmark, E., Palkopoulou, L. and Dalen, L. 2015. Ancient wolf genome reveals an early divergence of domestic dog ancestors and 
admixture into high-latitude breeds. Current Biology 25: 1-5. CrossRef

Trut, L. 1999. Early Canid domestication: the farm-fox experiment. American Science 87: 160-169. CrossRef

Trut, L. 2001. Experimental studies of early canid domestication. Pages 15-41 in Ruvinsky, A. and Sampson, J., editors. The Genetics of the Dog. CABI Publishing, New York, USA. CrossRef 